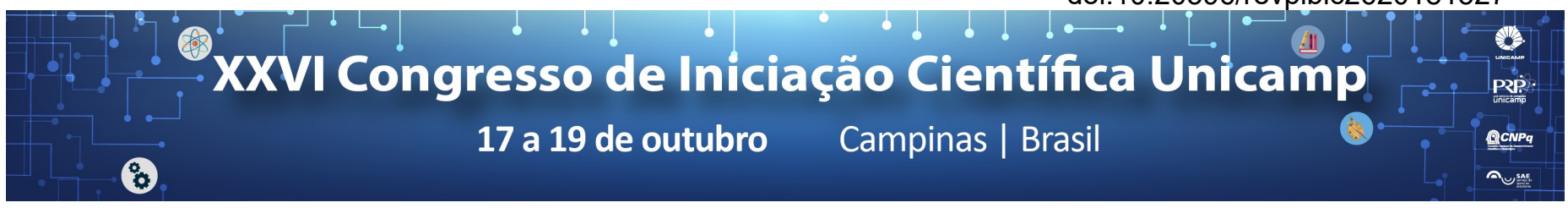

\title{
Uso de dados de radar meteorológico para o mapeamento da precipitação na Região Metropolitana de Campinas
}

\section{Tiago Vilar Ifanger*, Ana Maria Heuminski de Avila}

\begin{abstract}
Resumo
A presente pesquisa estudou a variabilidade espacial e temporal da precipitação na Região Metropolitana de Campinas (RMC). Foi realizado um inventário dos casos de precipitação que atingiram o volume de 80 milímetros em 72 horas, definido pela Defesa Civil como um evento intenso de chuva. Também foram analisados os danos causados pelos eventos intensos e comparado às relações com as áreas de risco dos municípios da RMC.
\end{abstract}

\section{Palavras-chave:}

Radar Meteorológico, Áreas de Risco, Eventos Intensos.

\section{Introdução}

Os eventos intensos de precipitação podem acarretar em prejuízos sociais e econômicos, afetando a população e o próprio município. Estudar e compreender a variabilidade dos eventos de chuva extrema pode auxiliar a Defesa Civil nas ações e planejamentos para lidar com tais eventos. Gonçalves (2003) analisou os efeitos dos eventos intensos em Salvador/BA e enfatizou que as soluções para tais problemas se dão a partir da aproximação dos órgãos administrativos e sociedade. $\mathrm{O}$ objetivo desta pesquisa foi analisar os eventos intensos que ocorreram na RMC durante o período de Dezembro de 2016 à Maio de 2017, coincidindo com a coleta de dados do Projeto temático Fapesp, SOS chuva.

\section{Resultados e Discussão}

Foram identificados 9 (nove) datas em que ocorreram eventos intensos, dentre as quais apenas uma atingiu o limite definido pela Defesa Civil, a precipitação acumulou mais de $80 \mathrm{~mm}$ em 72 horas. A Figura 1 apresenta a distribuição espacial da precipitação no dia 19 de Maio de 2017. Para a mesma data, os alertas recebidos pelas Defesas Civis salientavam que chuvas moderadas e fortes estavam se deslocando em direção aos municípios mais atingidos pelas chuvas, bem como alertou sobre o aumento da vazão do Rio Capivari dentro de Campinas e Monte Mor. As áreas de risco dos municípios da RMC estão mais vinculadas a alagamentos e inundações, poucos municípios têm risco de deslizamentos. No dia 19 de Maio houve registros de alagamentos e inundações em Americana, Campinas e Monte Mor, por decorrência de ventos intensos e quedas de árvores que foram registrados em diversos municípios, em análise os impactos registrados pelos meios de comunicação em outras datas, também estão vinculados às áreas de riscos.

A partir dos dados obtidos e analises, os impactos ocorridos pelas chuvas não se limitam apenas ao limite de 80 milímetros em 72 horas, outros fatores podem determinar que tais eventos sejam intensos e necessitem de medidas dos órgão administrativos. A depender da localidade e duração de um evento os impactos podem ser distintos para o mesmo volume de água precipitada.

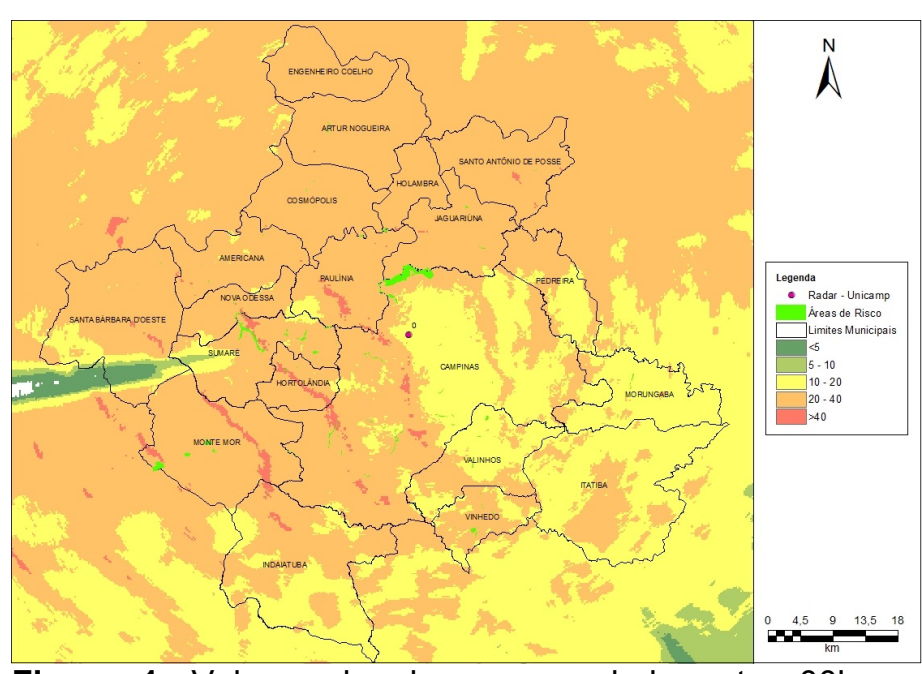

Figura 1. Volume de chuva acumulado entre $00 \mathrm{~h}$ e 23 h50 do dia 19/05/2017.

\section{Conclusões}

Conclui-se dessa análise que a utilização de equipamentos sensor de alta precisão, como o Radar Banda-X, é um instrumento importante para monitoramento de eventos intensos, auxiliando a mitigação de impactos e prejuízos que eventos extremos podem acarretar para a sociedade e órgão administrativos. Assim como, a utilização de alertas também se destaca como medida para mitigação, inventário de impactos e localidades dos mesmos também são dados fundamentais para que os órgãos competentes decidam sobre infraestruturas e outras medidas necessárias. É importante que seja feita pesquisas sobre essa temática e com maior detalhamento do perfil socioeconômico da população residente em áreas atingidas pelos impactos dos eventos extremos.

\section{Agradecimentos}

Agradeço ao Projeto temático SOS chuva, Processo 2015/14497-0 pelo suporte para realização da pesquisa.

GONÇALVES, N. M. S. Impactos pluviais e desorganização do espaço urbano em Salvador. In: MONTEIRO, C. A de F.; MENDONÇA, F. Clima Urbano. São Paulo: Contexto, 2003. v.1, p. 69-92. 